\title{
Transitivity and Bidirectional Framing in Telecommunication Advertisements
}

DOI: https://doi.org/10.47175/rielsj.v2i3.238

\section{| JOHN, Fredrick Friday ${ }^{1}$ | ATOLAGBE, Oluwadamilare Daniel ${ }^{2}$ |}

${ }^{1}$ Dept. of English, Chrisland University Abeokuta, Ogun State

${ }^{2}$ Dept. of English and Communication, Institute of General Studies, Kwara State Polytechnic, Ilorin, Kwara State

${ }^{1}$ proffysong@gmail.com / fjohn@chrislanduniversity.edu.ng

2oluwalex77@yahoo.com

\begin{abstract}
Advertisements are onerous ways of representing the identity of producers and consumers who are both agents of social life, and mobile telecommunication advertisement is not an exception. However, this has not attracted sufficient attention in linguistic studies. This study investigates the bidirectional framing of the identities of telecommunication service providers and the subscribers in twelve MTN and GLO advertisements, aired on popular mainstream television stations between 2014 and 2017. These were downloaded from youtube, where they are trended as unsolicited adverts to reach millions of users. The qualitative analytical approach was adopted, using transitivity, in the systemic functional linguistic (SFL) framework, as theory, to analyse transcribed texts from the advertisements. The findings show that copywriters use material, mental, verbal, relational and existential processes to frame service providers as welfarists, supremacists and benefactors/beneficiaries, and the subscribers as consumerists, opportunists and beneficiaries/benefactors. The supremacist' and welfarist' identities are used as indexes to establish the stiff competition between and among service providers to gain more subscribers. The results also show that welfare services are initiated as basis for out-doing self and otherself services. The enthusiasm of the subscribers to use services account for their framing as 'consumerists' and 'opportunists.' The beneficiary and benefactor identities are bidirectional, as both service providers, and subscribers mutually benefit from each other in a one-to-one relation. The study concludes that transitivity processes are indelible linguistic resources used in telecommunication advertisement to bidirectionally frame the identities of service providers and subscribers, with a view to enhancing consumerism.
\end{abstract}

KEYWORDS

advertisement; transitivity; identity; consumerism; telecommunication discourse

\section{INTRODUCTION}

The intricacies of globalisation and advancements in technology that have characterised the world in recent times have obviously extended the debates in the field of advertising. This, to a large extent, have attracted social, political, economic and cultural importance to advertisement both as a concept and a material for research. According to Williams (1980), advertising enhances our comprehension of 'different generations of cultural observers.' This because of the social and cultural undertones that are alluded in the fabrics of advertisement pieces Steven. With this in mind, classifying advertising as an industry in its 
own right, and attributing it with the status and function of serving as the aesthetic eye of viewing human behaviours and identity in popular culture would not arouse any controversy. Wernick (1991) asserts that advertising takes the forefront when it comes to expansion of the global economy and postmodern promotional social and cultural rites, for the purpose of stimulating consumption (Featherstone, 1991) and (or) mobilising patronage of particular products and services.

Davidson (1992:3) puts it that it is 'a social language,' particularly, the peoples' language of communication. Inherently, there is a form of identity in language itself. People are identified by the language they speak, their statuses and positions, are also situated within the frame of advertisements or commercial. In another pedestal, advertisements construct sequences of experience, in this case the positions, conditions or situations and activities that are indexed to consumers' day to day life, on the one hand, and the activities of the producers, what they are doing to get products and services to their customers, on the other hand. The same can be said of telecommunication advertisement in the Nigerian sociological milieu, though not much attention has been paid to this in linguistic studies of advertisement, which has necessitated this study. Telecommunication advertisements are also conditioned by social life, that is, peoples' experiences and values, and most significantly, the way they live, and the world they operate in.

Going by Vahid and Esmae'li's (2012:36) conceptions, advertisements express power and ideology of the producers, in their quest to change consumer's 'behaviour, thought and will,' using persuasive techniques (Davidson, 1992:3). In order words, the class position and status of the service provider is seen through the inferential indexation of agents or brand ambassadors, that are used, not only to reaffirming the advertiser's or producer's objective to to persuade or lure users to use the product, but also assert the product's power, which is a branch of economic or commercial hegemony. Cook (2001:3) asserts that these are achieved by fictional representations, 'word play, compressed story-telling, stylised acting, photography, cartoons, puns and rhythms,' among others. Embodiments of these strategies, in potential advertisements, compact the language of advertising, and blur the attention of the users from identity relations in the advertisements. The focus oscillates between the aesthetics of style and discourse in the advertisement, on one hand, and consumers' responses or behaviour, not just of the products advertised, but the spontaneous enjoyment, of the advertisements, on the other hand.

Steven, David and Jay (2005:2) opine that advertising constitutes the 'conceptual model that traces the life and meaning of cultural commodities.' To them, advertising is procedural as it displays producers' activities, that is the processes and transition through various processes and production phases, representation, regulation, and subsequently the channel of consumption. The processes show specifically how their identity as a brand and that of the consumers the product or service is designed for are shaped. It therefore follows that advertisements and commercials are mediating tools in the hands of copywriters of advertisement agencies present the respective identities of the producer and consumer, in most cases, profiling cultures and world views of the socio-cultural milieus where the product and advertisements are set. Giroux (2000) and Miller (1995) relate this form of profiling to the bidirectional historical transformation between the capitalist system, which is driven by production, and commodification or consumerism, which is based on consumption. It therefore posits that advertisements are both producer and consumer oriented, but much focus, in the literature, is either on the advertisement or the product's or consumer's behaviour. This present study brings the producer, in this case, mobile telecommunication services providers, into the equation and focuses on the bidirectional 
framing of service providers' and service subscribers' identity in selected MTN and GLO advertisements.

\section{LITERATURE REVIEW}

\section{Identity and studies on identity framing}

Identity is a ubiquitous nomenclature, with diverse definitions and implications in social sciences, from psychoanalysis to psychology, political science, sociology, anthropology and language. The meanings and implications of identity could be viewed from its conceptual and theoretical role. For instance, in sociology and social psychology, three relative nomenclatures are attached to it; these are: as the culture of a people (Calhoun, 1994), common or collective identification of actors (Tajfel, 1982), and the representation of 'self' (Habermas, 1990: 200; Giddens, 1991). The first relates to culture system or the representation of ethnic identity. Thus, when viewed with this eye, identity is indistinguishable from ethnicity. The second annexes the collective and all-encompassing notion of identity to revolve around contemporary social, economic and political situations, in fact all areas where there is collective or bidirectional relationship between and among individuals who share the same social experience. Thus, we can categorise identity into social, religious and political paradigms. The third category implies, on the one hand, symbolic interactionism (Mead, 1934), where an individual's identity is a form of heritage, and is projected in his/her norm of interaction, and the individual's 'lifestyle' (Giddens, 1991), on the other hand. One's identity is not distinct from one's lifestyle.

Critical representation of identity shows, first, according to Habermas (1990: 200), that one's identity is not subject to his own representation of oneself, claiming that 'no-one can maintain his identity by himself.' But since identity is sometimes reflective by a conscious behaviour, and human behaviour account for some forms of identity, it cannot be called to question that one can consciously or unconsciously represent one's identity through discourse or behaviour. Second, identity is not formed or sustained in isolation; it is connected or interconnected with collective systems of people's beliefs and practices, and according to Schiffrin (1994:371), language, which is used to organise or reflect the organisation of beliefs, norms and social life, acts as a dominant vehicle for projecting group's identity. The implication of this is that identity is used to reinforce socio-political, religious and cultural groups, and revealing of their lineage, clan, tribe, nationality, and political class, among others. This goes to show that there is interconnectedness between social life, that is, the social structure and the identity frames of social actors in it.

Deaux (2000) opines that identity is operative within basic principles, and the same principles determine how identities are represented and subsequently interpreted in discourses. The implication here is that identity resonates or is generalised among participants or social actors, as long as they are aligned to the group and display all the interactional and behavioural tendencies recognised with group. This is why identity is always considered along the paradigms of in-group and out-group participants. Social identity can also be the 'self-structure' of individuals (Reid and Deaux, 1996; Stryker, 1987), the character of inter-group relations between the in-group and out-group (Taifel and Turner, 1979) or the relationship of other agents to the broader social structure (Breakwell, 1993; Moscovici, 1988).

Social identity is constructed based on social contexts, but Worchel Iuzzini, Coutant and Ivaldi (2000:17) argue that it is a form of psychological - cognitive models, existing as a mould that the social agents have been fitted into, hence, the treatment of identity as a cognitive process of categorisation or comparison, of (between and among) social and 
political agents. However, this does not change the fact that identity is conceptual (Cronin, 2000:19) and considered as a branch of the social structure or system.

Warner (2000:64) posits that 'it is rarely possible' to be able to distinguish between collective and personal or individual identity. This is because, as said earlier, individuals' identity is not in a vacuum. This merely reinforces Giddens' (1991: 53-55) assertion that mutuality in identity is a critical theory of modernity, where a person is not only a reflexive social actor of a group's identity, but also an embodiment or model of identity attached to that form of biographical narrative. If identity determines a group's narrative, it therefore means that it is a reflection of what humans belonging to each group do (Martin, 1995; Malešević (2004). what people do form the basis for their identity.

Another way to look at this is to bring in the notion of group interest. This subsequently means that Interest and identity are intertwined, and whatever involves identity reflexively involves interest. However, it cannot be completely dispersed that, in some instances, people may pursue certain interests that do not align with their individual or collective identity. For instance, identity and collectivism are indexes to the way individuals often negotiate or pursue their own interests. Subsequently, the pursuit of their interest becomes indicative or reflective of their cleavages and ties. Cronin (2000) opines that in the bid to promote the interest of goods and services in advertisements, the copywriters pursue two shades of identities that are not theirs, but the people they represent. Thus, identities of various forms are expressed in advertisements.

\section{Theoretical Framework}

Transitivity is correlates with the ideational function of systemic functional linguistics (Young and Harison (2004:3). Fontaine (2013:73) argues that it "is the foundation for any analysis within SFG framework", implying that transitivity has a special function or meaning in the functioning of systemic functional linguistics. It is what helps in the derivation of the full analysis of the clause as representation of existence. Arguing further, Fontaine opines that transitivity is central to any analysis of the clause. Hence, the best way to start the analysis of the clause is by looking at transitivity as the foundational basis of the clause, which is the expression of meaning.

Halliday and Matthiessen (2004:280) put it that transitivity represents process types of participants and the 'participant functions' associated with each process in the clause. Viewing the clause as representation means that, in any form of clause, we can identify certain agents who play significant roles in the structure and (or) meaning in the clause. Different processes are involved, and 'each type of process is characterized by processparticipant configurations' (Halliday and Matthiessen, 2004:280), having particular functions. The processes we are talking about here relate to the verbs, which are either transitive or intransitive (or copular), depending on the occurrence or absence of the participants (Fontaine, 2013:73), in the traditional sense, objects which can be direct or indirect depending on the nature of the participants allowed by the process.

Transitivity, as an analytical framework in systemic functional linguistics, is described as "the grammar of process... and participants in the process, and the attendant circumstances" (Halliday, 1978:30), that is, the context in which the participants find their affordances (Mey, 2001). Transitivity does not just focus on the verb (process), it applies to the whole clause; it extends beyond the process and participants to the level of circumstance, that is, the experience which is also the sociocultural context (of situation). Halliday, $(1967,1994)$ outlines six transitivity processes, which are 'material, behavioural, mental, verbal, relational and existential processes.' Each process has its own grammar form, but at the level of interpretation, they all have the same grammar since there is only 
one generalised representational structure common to every clause, and the same overall goal, which is: the clause as representation of experience, in this case, the identity of social actors. The figure below, which is the model for our analysis, shows the variables of transitivity processes that have been co-opted for this study, and the identity variables that they frame in advertisements.

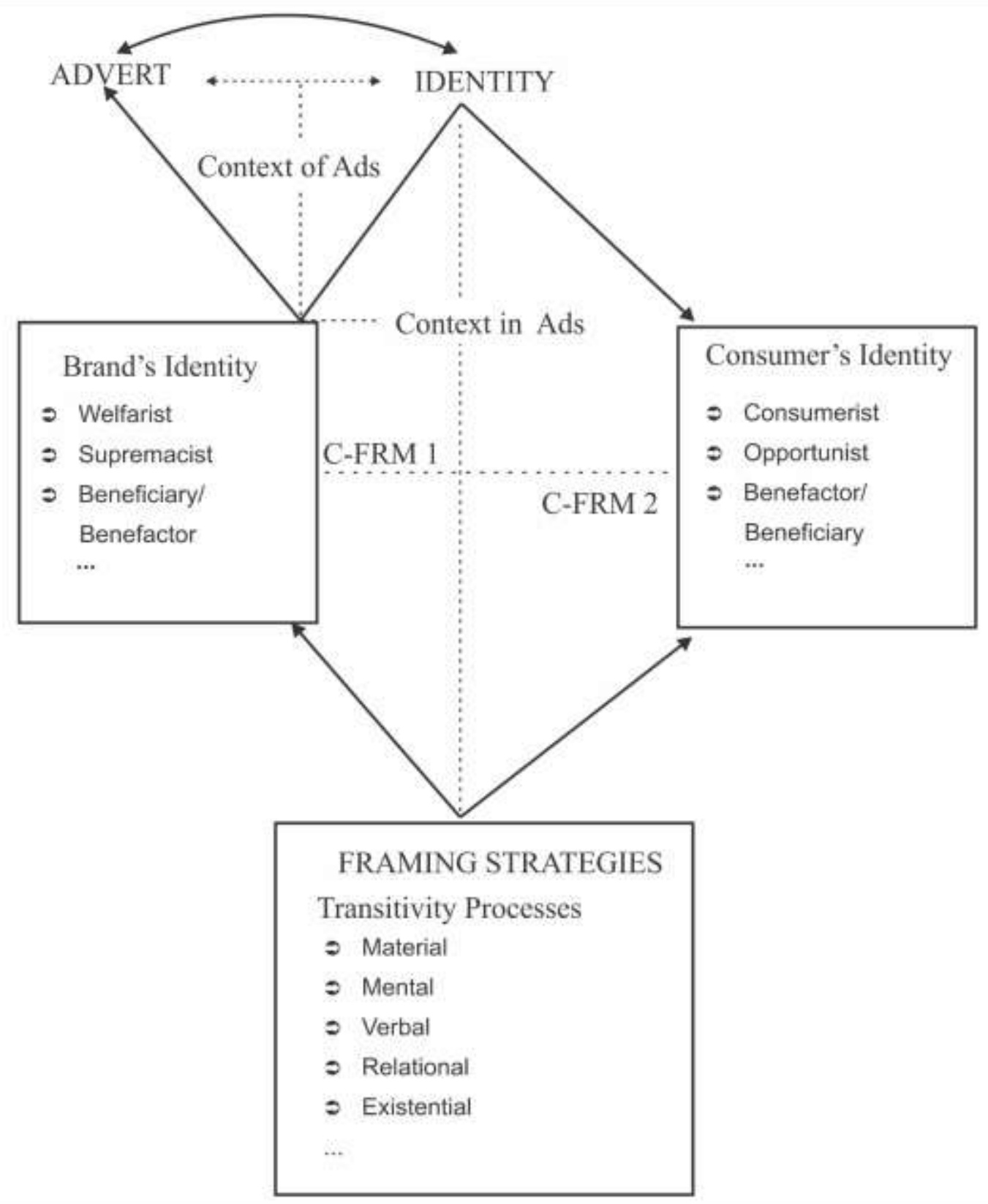

Figure.1 Identity framing in advertisements (Source: Mine)

\section{RESEARCH METHODS}

Twelve (12), among about thirty-five (35) MTN and GLO advertisements, which were aired between 2014 and 2017 in popular mainstream Nigerian television stations, were purposively selected and downloaded from youtube video, where they remain in the public domains for viewers and researchers. GLO has been the strongest competition of MTN in the mobile telecommunication sector in Nigeria, and the most fervent ground for 
competition between them is advertisements, which conditioned the selection of the data. The data were transcribed into texts, and then analysed qualitatively, using the top-down analytical approach. The theory of transitivity, which is suitable for identifying participants and processes, which are not too distant from identity relations, is used to analyse the textual data, as reflected in the model in fig. 3.1. above. Depending on the contexts of and (or) in the advertisement (ad), the copywriter's identity frame (C-FRM), may be bidirectional, especially in the material process, or exclusive, that is (1 or 2 or both). Translations were provided for all the pidginised expressions in the data before their analyses.

\section{Data Analysis and Findings}

Transitivity plays an important function in the representation of identity and experience in MTN and GLO advertisements. They identify, among other things, the role relations of the service producers and the subscribers in the fight to expand producers' capital base. The transitivity processes identified in the data, and subsequently discussed in this section, are: material, mental, relational, verbal processes and existential processes. We begin the discussion with the sequences of material processes

\section{Participants and identities in material processes Excerpts:}

1. (You) just recharge your Glo line with N200 (GLO Recharge to stardom promo) Show us the way ( $G L O$ recharge to stardom)

2. If you buy recharge card (of) $\$ 1000 \ldots$ Get an MTN SIM, register it Bros, abeg show me the way na (MTNS yafun yafun bonus)

Trans.: Please, vendor, show me how to geet the service

In the above excerpts we have the economic interest of the service providers is viewed as the context of the advertisement. This is construed by the request to buy and recharge airtime. The subscribers are identified as 'actor', physically and situationally represented by interactants in the advertisements. In sample (i), we have the 'actor', 'benefactor', and 'goal' sequence. The entry for the 'actor' is implied by the anaphoric possessive pronoun, your, which is also used to modify the benefactor. Indirectly, this points to the service provider as the 'beneficiary,' because when the GLO line is recharged with 'the goal', $\$ 200$, it is the service provider that profits, the subscribers only have the benefit of calling or qualifying for any other attached welfare benefit, as promised by the service providers. The service providers are literarily situated in context as well as the system using SIM or line, being synonyms. Without this, subscribers cannot use the service. GLO and MTN are also contextualised as carriers of the identity.

Also, the particular description of the worth of airtime that the subscribers need to recharge on their phones to qualify for the benefits are stated. Directly, this is used to portrayed the subscribers as consumerist. By purchasing and recharging their GLO line and MTN SIM with the goal, ' 1200 ' and 'N1000, the subscribers increase consumption, while they enrich the service providers in the process. Thus, indirectly, this represents the service providers as beneficiaries of not only subscribers' patronage, but also the resources used in using the services. In excerpt (2), the material process shows the act of desperation that is connected with the opportunist identity. Here, the advert, simply, justifies the assertion that what attracts the subscribers to the service of the service providers is the beneficiary welfare services provided by the service providers. The actor agent, co-opted from the Pidgin lexicon, Bros, is a symbolic index to the service provider, while the scope, the way, is the welfare package offered. This labels the service provider as a 'welfarist.' The goal, 
$m e$ frames the subscriber, who is represented by another social agent, as 'opportunist,' who is desperate to get welfare package from the service provider.

\section{Excerpts:}

1. You go enjoy bonus brekette.../...Dem go give you $\$ 600$

Trans. You will enjoy sufficient bonus of airtime... they (MTN) will give you $\$ 600$ ) (MTN yafun yafun bonus)

2. You get AMAZING Extra value (MTN Extra Data bundle)

The material is used to project the subscribers offering material benefits to subscribers for services. In the first clause in (3) and (4), the network providers are framed as welfarists, using the goals in the material processes, while in the second clause in (3), it is represented by the actor participant. Here, the actor is seen as a welfare rewarder, who acknowledges the consumption of the subscribers, and wants to give back something in form of reward - welfare package. The subscriber, on the other hand, who is indexed as the actor of the first clause, and the goal of the second clause, is represented as opportunist and beneficiary of the welfare service. In the first place, as an opportunist, the subscribers are said to enjoy the service, which is believed to be giving on a platter of gold, at least when weighed with the subscribers' input. For instance, in some cases, the benefits are said to be four (4), six (6), or eight (8) times greater than their investment in the service. These benefits, in sample (4), are lexically aggrandised, using the adjectives, AMAZING and Extra; the former is obviously stressed and stretched, as indicated using the block letters, while the latter presupposes that the subscribers are using services that exceed what they pay for. This 'goals,' strongly position the subscribers as opportunists and the service providers as welfarists.

\section{Excerpts:}

3. So choose the size that sooths your needs (MTN Extra data bundle)

Opportunism, in advertisement can be related to social class disposition. This is further used to reinforce the supremacists' identity of the service providers and the consumerists' identity of the subscribers. From the point of the subscribers, their consumer power is signified by their purchasing power, having the will-power or position to choose the services they want to use, when and how. The goal, the size, signifies that there are options of services cut across every network service. There is also a correspondent notion that each option is designed, considering a number of consumer-conditions, among which is their affordability of the services. Subscribers can only make choices considering their means, on one hand of the coin, and the benefits attached to that option, on the other hand. This brings us to the issue of the scope, which subsequently has a phenomenon, your needs. This represents the service providers, in this case MTN, as welfarists. The inference is that the service providers have several welfare services, that is sizes, which are designed to meet the needs, consumption capacity of the subscribers. They (the subscribers) are not expected to make choices conventionally, but considering their need, which thus, makes them beneficiaries. It goes further to posit that it does not matter their class distribution, there are available services they can be beneficiary of.

\section{Participants and identities in the mental processes}

In general sense, the mental process is 'sensory based' and focuses on the human neurocognitive abilities of knowing, seeing, hearing, thinking or deciphering (Fontaine, 
2013:82). Relating the above submission to this analysis, the mental process is hinged on the cognitive articulation of identities, in most cases, using direct, indirect, psychological, conversational acts, and inferences. The two main participants in the mental process are the 'senser' and the phenomenon. Identity is indexed mostly to both the 'senser' and phenomenon.

\section{Excerpts:}

4. but that looks like him, can't you see his big head!... Would you like to have a drink? (GLO Recharge to Stardom)

5. I need a SIM, so I can have a number...

One of the goals of advertisement is to spring surprise, especially at the first sight of the advertisement. In some cases, it even takes time before the viewers are able to place the acts or events in the specific contexts. Brands, the service providers in this case, often use brand agents to symbolically index their identity and the subscribers' identity. For instance, in excerpt (4), there are three (3) men, including the celebrity, Desmond Eliot, acting as the principal subscriber agent. The cognitive process of surprise is established, Bobo (Desmond Eliot), who used to hang out with them no longer does, as a result of change in status, which the service providers are given the credit for the transformation, which is represented as a phenomenon. Now, he is not just hanging around, but buying them drinks. This presupposes the service provider's identity as a 'welfarist'. It is further inferred that the beneficial service provided by the service provider is the earns the subscribers a change in status, making them fit into the identity of beneficiarist. The metaphorised description of 'Bobo', with the phenomenon, big head' signifies this change in status from a common subscriber to a celebrity. The 'senser,' the pronoun you, refers to the curious and prospective subscribers, who are opportunists, willing and anxious to join to annex the phenomenon, which is 'to have a drink'.

In excerpt (5), the focus is on the subscriber, who is labelled as 'consumerist.' The senser, represented by the reference $I$, is said to be desperately in need of the phenomenon, a SIM, which is also described as number. Without this, first she cannot have access to the benefits that are offered by the service providers, and second, she will not have opportunity to connect with acquaintances, friends and family. As the consumerist, the subscriber is operating first at the level of conventionality of choice. She just needs to connect, but subsequently, she gets to know that there is a buoyant welfare package, which then conditions her choice of 'need.' When viewed from the point of the basic necessities of life, need is beyond want, and it is condition with an obligatory condition. For instance, it is obligatory to have food and shelter to enhance survival. The implication is that mobile telecommunication services, in contemporary life, has been considered as a life, and the desire to connect with people is a basic necessity. This is the hallmark of the consumerist identity, and this manifest by (in) the strong attachment most subscribers have with their phones, calling and charting, among others.

\section{Excerpts:}

6. ah...! Oh! No! do youth know yet?... Guys, I think we've lost the war! (MTN pulse)

7. This place look like Glo restarant for your eye abi... (GLO free tomorrow, Buka)

Trans: Does this look like Glo restaurant to you? 
The first utterance indicates the competition - battle among network providers for subscribers. This is used to, also indirectly, establish the supremacist identity. To win more customers and achieve their hegemony over other brands or service providers, each service provider projects promo or value-added services, which is acclaimed to 'outclass' similar packages of their close competitors. For instance, in excerpt (6), the senser, 'youth' refers to the subscriber, in this case, the deitic center, represents one of the primary target-classes of the service providers. It is believed that the youths use more, particularly, data services, welfare or free service packages; hence, are a huge factor in accounting for the subscriber base of the service provider. Thus, there is more competition to attract this group to assert economic hegemony over others. The phenomenon, yet, represents the time index that is needed to attract the senser, the youths. The second speaker, who is a symbolic metaphor for one of the competitors, represents the stiff competition among the network service providers to capture the market, and the youth-class as war, which is the phenomenon. Economic 'wars' are inherently displayed in every service provided by the service providers, from call rates to data packages as well as bonanza or promo packages. One of the wars the senser may allude to is the struggle of MTN to take back the market from GLO, who had attracted the vast majority of subscribers with the introduction of persecond billing.

In excerpt (7), an irony is used by the speaker, who is iconic of another brand or service provider, to establish ignorance of the service package offered to subscribers by GLO, in this case. Here, the senser, a woman, representing the subscribers, has just finished consuming a bumptious meal at a restaurant, which is also a metaphor established for the service providers. They are the ones selling the food the subscribers are consuming in forms of data, and caller services. The inference here is that only GLO can offer the free service package being advertised, which reinforces the supremacist identity.

\section{Excerpts:}

8. when you think of it; There's no such thing as a right size ... Our needs are different (MTN Xtra data bundle)

9. ... who needs more than one (Glo 3 in 1 recharge)

The service providers, as said above, construe supremacy by packaging, in order of hierarchy, various beneficial services for subscribers to be able to choose from. In some cases, the subscribers are required to consider, among available options, which the they (service providers) acclaim would sooth their need. Take for instance, in excerpt (8), the subscribers, which is the senser of the mental process, is prompted to register in their cognition, the existent, that communication needs are different from one subscriber to the other. Hence, the 'phenomenon,' which has the keyword, the metaphor, right size, expresses the hegemony of class in the system of consumption, not service delivery. In terms of service delivery, it represents multifariousness of products or service packages, all designed to meet different needs. The phenomenon, within the framework of competition, also imply the difference in position, that is supremacy of the service provider to other competitors.

The rhetorical mental process is used to signify hegemony or supremacy of the brand's service package, the GLO 'pin,' which is the most supreme entity that connects the subscribers with the service providers, apart from the sim card. The pin is at the centre of all activities that the mobile phone service can be used to achieve, without it there cannot be calls, browsing, texting, pinging or any form of activity. Also, it is at the centre of every bidirectional welfare service the service provider is offering the subscribers. For instance, 
they have to get pin, which has other nomenclatures like airtime, recharge card and data, to be able to access any service. Apart from the supremacist identity of the pin, there is also the supremacist of the brand. For instance, the senser, the relative pronoun ' who,' is rhetorically emphasising that only one network and one service, which offers privileges than the others, is needed by every subscriber. In other words, once subscribers have this particular brand, and its product, there is no need to have another, which is in the phenomenon, more than one.

\section{Participants and identities in the relational process}

The relational process has two pivotal processes which are: the attributive and the identifying processes. The attributive process has the carrier and the attribute; it is mainly used to describe, re-describe and appellate the participants that serve as the carrier, which can be indexed to the network providers or subscribers in mobile telecommunication advertisements. On the other hand, the identifying process has the identifier and identified sequence, used to identify functions, relationships or positions of subscribers and service providers in advertisements.

\section{Excerpts:}

10. Oga this suya plenty o... you no dey pay today, na free tomorrow na!

Trans: Customer, this (meat) is much... you are not supposed to pay today, it is free tomorrow! (GLO free tomorrow, Suya palava)

There are two relational processes in excerpt (10). The first is in the attributiverelational process, stating the intensity or quantity of consumption, in this case, use of the network service, which is said to be a welfare package. Thus, while the subscribers are labelled as 'consumerists,' the service provider is labelled as welfarist. They (the service providers) are the ones who provide the carrier, Suya, to be consumed or used by the subscribers. The carrier here is metaphorise, for the purpose of emphasis and isolation of the context of materiality. All of the services, sim, pin, data, among others attached to the services are materialistic in nature and could be acquired and used. The meat seller's statement implies that consumption, the attribute, plenty, is more than what the subscribers can pay for, which means that he is opportunistic of such a beneficial service of free tomorrow. This further strengthens the identity of the subscriber as welfarist and modifies the subscriber's identity as an opportunist.

The second relational process is in the identifying process, which is stated in the concluding parataxis clause. The service package is indexed by the reference pronoun ' $i t$,' which is the identified, also reflects the network providers' offer of welfare packages, 'free tomorrow,' which is the identifier. The service implies having freedom to make free calls after paying the previous day.

\section{Excerpt}

11. Sister! So you be area na him you kan dey form like this! (MTN yafun yafun bonus)

Trans: Sister! So you are one of us; you were just pretending!

The identifying-relational process is used, in excerpt (11), to mark the true identity of the prospective subscriber, at the sight of a service benefit. The 'identified' which is reference pronoun ' $y o u$,' refer to a novice subscriber, in this case a lady, who claims to be a returnee from the United States of America. Here, the mobiliser agent also poses as a 
subscriber, and has just shared his experience of the enormous service benefits of that particular network service. This forces the lady to swap from her pretensive or adopted code to her original code, which is pidgin, condescending her class for the purpose of benefiting from the service. This marks her as an opportunist, desperate for the offered promo service. The identifier, area, is used to reinforce the context as well as show the true identity of the lady as, not just a Nigerian, but a local. Two inferences are subsequently activated by the identifier in relation to the labelled identity of 'opportunist;' the first is that benefits attached to services, despite that they are designed for specific classes, are annexed by other classes. For instance, free services are used by even those who can afford to pay for them. The second inference is network service packages are designed to carter for the service needs of everybody, that is, give, all class variables in the sociological milieu irrespective of where they are from. The network services have spread vastly to almost all local communities in the country to give, even the locals opportunity to connect with the global world.

\section{Participants and identities in verbal processes}

The verbal process deals with articulating experiences that involve 'saying,' telling,' 'verbalising,' or 'reciting'. There are three participants sequenced in the verbal process. These are: the sayer, the person uttering the statement or representing the utterer as in the case of MTN and GLO advertisements; the receiver, the person or group of people that are being addressed, and the verbiage, which is the content of what is said.

\section{Excerpts:}

12. Call me back, No be wetin you dey tell me anytime wey you manage call me Trans: call me back, is that not what you tell me whenever you manage to call?

(GLO Jollof, Pidgin version)

13. today, my calculator tell me say you even send plenty SMS to blessing; and even follow blessing talk for a long time

Trans: My record teels me that you sent SMS to Blessing and even called her for a long time (GLO free tomorrow, who be blessing)

Excerpt (12) shows a negotiation between two friends, who are indexical to the subscriber agents. The receiver is the personal pronoun, me, referenced to the novice subscriber, on that has no initial idea about the service. In most cases, subscribers act as mobiliser agents to services or packages, propagating the news of such services to their friends and family members. By so doing, they help to spread consumerism. The 'sayer' in the clause is in the second person pronoun, 'you', referring to the mobiliser agent (also a subscriber), who has equitable knowledge of the service, and subsequently, using at the same time promoting the service to the subscribers. The verbiage has another verbal process with the inference that subscribers exploit one another when they call, especially when they are calling from another line. The limitation here is on the high call rate that is required for inter-connecting calls. Thus, it also indirectly implies that one way to establish supremacy or hegemony of their service is to enhance more intra-connecting calls, and discourage inter-connecting calls. This is the hallmark of competition, trying to displace one another. The 'call me back' service is an MTN package, while the Jollof recharge is customised for GLO, and is considered to be superior. The mobiliser agent is labelled as a beneficiary of the Jollof offer.

In excerpt (13), the subscribers are represented as consumerists, implying that the service provider takes record of their (subscribers') daily consumption of services. and subsequently, as a welfarist, rewards them for their patronage. The relevant input of 
calculator, which is the direct 'sayer' in the verbal process, is used symbolically to quantify the subscribers' usage or consumption of the service. In the economic context, a calculator is used to sum up larger figures that could not be arrive at by simple intuitive calculation. This implies, though indirectly, that beneficial - promo services also require money, sometimes, a huge sum of airtime. For instance, the service involves using airtime and data the previous day and the volume of airtime the subscriber use, would determine the rate of welfare benefits they qualify for. There are two verbiages in the utterance used to reinforce the subscribers as consumerist and enumerate the aspect or variable of use of the GLO services, that is, to 'call', 'text' and 'browse'. The 'sayer' is cast as a magician and this coincides with the rrepresentation of the service provider as a welfarist. A magician makes viewers happy by conjuring up things, sometimes, multiplying certain objects for amazement.

\section{Participants and Identities in the Existential Process}

The existential process is used to relate experiences that are in existence. These processes are either identifiable or traceable to the context of occurrence or relevance, especially in the instance of use in advertisements. In meaning relation, the existential process relates to the concept of truth or falsity condition. Hence, we may have positive existence and negative existence, for instance, when the negator, not is used. In MTN and GLO advertisements, the existential process is used to create or represent the cognitive or illusionary idea of existing welfare or beneficiary services, which are the main identities represented in the existential process in advertisements of mobile telecommunication services.

\section{Excerpts:}

14. ... this one no be Glo Suya spot; free tomorrow he never reach here

Trans.: This is not GLO Suya sport. Free tomorrow is not here.

15. Na lie, he dey everywhere. (GLO free tomorrow, Suya palava)

Trans : it is a lie, (free tomorrow) is everywhere.

16. there's only the size that's right for you... (MTN extra data)

Excerpt (115), using the existential process, shows the control of the service provider over territorial spaces, which also enhances its representation as a supremacist. The hegemony of the brand is further expressed in a counter - positive existent, as a conversational repair of the initial negative existent, expressed by the vendor in excerpt (14). Here, the Suya vendor, who is supposed to be indexical to the service provider, denies the existence of the service package, free tomorrow, which is the existent, using the pidgin negative marker, no be and never, for 'not.' However, this is considered as a brand strategy to build emphasis around the existent, as it becomes the foundation for the repair in (15). The existent, is indexed with the adverbial - spatial-temporal index, everywhere. The report is that there is GLO welfare service and benefit in every local communities in the country, basically to show the vastness of the service at that particular time of reporting. The existent is derived from the linguistic context of the presiding utterance made by the suya vendor.

The conceptual identity of welfaristis is represented in excerpt (16). The emphasis here is on the existent, size, which stipulates the design of the service to serve as palliative for the subscribers' needs. The choice of the adjective 'size' as the existent stipulates that subscribers' usage of the service is heterogeneity, that is, they have different communication needs or different ways they use the service. Subsequently, it shows that 
the service providers, on the other hand, has available services to meet every need, cut across the regions and communities where their service is used for various purposes, which have been mentioned elsewhere in this study. The existent also reinforces that there is diversity in the social status of subscribers, which, to a large extent, determines the subscribers' ability to use the services provided. This is implied in the identifier, right for you.

\section{Excerpts:}

17. (GLO is) the next generation network!

18. MTN, (is) Everywhere you go!

In excerpts (17) and (18), the existential process is used in the brand's ideology, which is their strong selling point in establishing their hegemony. It has already been established that each brand, that is, service provider, strives to out-do the others and claim superiority of a wider space or coverage. From the existent in excerpt (17), it is signified that GLO's supremacist identity is tied to the spatial and temporal index of modernity and civilisation. The hub of civilisation is said to be globalisation through communication and the ability see and connect with the world. Using the adjective, next, to modify the existent, however, rather than make the network a second fiddle, establishes two conceptual implicaure. First, it is portrayed as a network that keeps evolving with the current trend of globalisation and communication needs. For instance, communication trends keep evolving and for the service providers to be relevant, they must keep up with the trends. The second implicature is based on the users themselves. The next generation are often indexed as the youthful generation, who are more dynamic in their use of the services provided. Their ability to choose among the services and brands is hinged on the ability of the brands to meet their usage demand. GLO here claims to be the right brand to meet that communication demand.

The same inferences are carried over to the existent in excerpt (18), but in different signification. The spatial index, everywhere, used to modify the existence of MTN services, is not limited to the spatial location. Rather, being in the indefinite sense, it presupposes, first, that anywhere one goes, in the nooks and craning of the country, whether rural or urban, among cliques and classes or groups, among others, one is able to use the network to connect with friends, family and other acquaintances. Second, it implies that the dominance or hegemony of the brand, particularly in relation to network - service, MTN in this case, exceed others. One of its acclaim is that it is the largest network in Africa, and that, as a result of this, there are, at the least, MTN users in every urban and rural communities, in every African nation it has its presence.

\section{CONCLUSION}

The study has focused on identifying subscribers' and brands' - service providers' identities that copywriters of telecommunication advertisements represented in one of the formative eras of the stiff competition, especially between MTN and GLO. This is evident in the supremacist identity that they are represented with. This insinuation is particularly inherent in them as a brand-identity, MTN, everywhere you go and GLO, Next Generation Network. A lot of services were also, during the periods covered by the study, initiated to assert or reinforce the supremacy of individual brands over each other, as well as other brands.

One other finding is based on the fact that, at this era, these networks engaged more promo and bonanza services to propagate services and, consequently, expand their 
subscriber base. By doing so, they portrayed themselves as welfarists and benefactors. As welfarist, they are said to be concerned with the welfare and needs of their subscribers. Thus, they offer extra services, gift services and reward services, averring the subscribers' identity as beneficiaries. In stipulating the benefactor identity of the subscribers, particular roles are stated such as, who gives what to who, in this case, the service providers giving directly to the subscribers. But in some indirect or ironical cases, the benefactorbeneficiary identity is bidirectional. For instance, bonanza and promo or gift services offered by the service providers are not totally free. Subscribers have to pay certain amount, in form of buying airtime or data, before they can qualify. It therefore posits that the service providers are beneficiary of what is spent by the consumers in the same way the subscribers are beneficiary of the gift or extra packages attached to the services.

The subscribers justify their identity as consumerist by patronising or using the services that are sold to them, most times with agitation and zest, as represented by mobiliser agents in the advertisements. In some cases, the enthusiasm they display in using free and bonanza or promo services account for their representation as opportunist. Evidently, most of them rush to benefit from these services before they are faced out, as most of these services are not permanent, bit for a short time to achieve the greater purpose of expanding their (the service providers') subscriber and capital bases. When their aims are achieved, they quickly move on to other ranges of services, which are also represented in the body of the advertisements as welfarist's tendencies, that is, having various service packages that soothe the consumption and beneficial needs of subscribers of various classes, groups or cliques. The study, thus, concludes that every form representation in telecommunication advertisements is A linguist means to portray the identities of service providers and users in a bidirectional manner.

\section{REFERENCES}

Breakwell, G.M. (1993). Integrating paradigms, methodological implications. In Breakwell, G.M. and Canter, D.Y. (Eds.) Empirical Approaches to Social Representations. pp. 180-201. Oxford: Clarendon Press.

Calhoun, C. (1994). Social theory and the politics of identity. Cambridge, MA: Blackwell. Cook, G. (1992). The discourse of advertising. London and New York: Routledge.

Cronin, A.M. (2000). Advertising and Consumer Citizenship: Gender, images and rights. London and New York: Routledge.

Davidson, M. (1992). The consumerist manifesto. advertising in postmodern times. London and New York: Routledge.

Deaux, K. (2000). Models, meanings and motivations. In Capozza, D. and Brown, R. (Eds.) Social identity processes: trends in theory and research. London: Sage Publications.

Featherstone, M. (1991). Postmodernism and consumer culture. London: Sage.

Fontaine, L. (2013). Analysing English grammar: A systemic functional introduction. Cambridge, New York: Cambridge University Press.

Giddens, A. (1991). Modernity and Self-Identity. Cambridge: Polity.

Giroux, H. (2000). Stealing Innocence: Corporate Culture's War on Children. New York: Sage

Habermas, J. (1984). Theory of communicative action. London: Heinemann.

Halliday, M. (1967). Notes on transitivity and theme in English (Part 1). Journal of Linguistics. Vol. 3,

Halliday, M.A. (1978). Language as social semiotic: The social interpretation of language and meaning. London: Edward Arnold. 
Halliday, M.A. (1994). An introduction to functional grammar (2nd ed.). London and Melbourne: Arnold.

Halliday, M.A. and Matthiessen, C. (2004). An introduction to functional grammar. (3rd ed). London: Arnold

Malešević, S. (2004). The Sociology of Ethnicity, London: Sage.

Martin, D.-C. (1995). The choices of identity. Social Identities, Vol. 1: 5-20.

Mead, G. H. (1934). Mind, self, and society. Chicago: University of Chicago Press.

Mey, J. (2001). Pragmatics: an introduction. USA: Blackwell.

Miller, D. (1995). Acknowledging consumption: a review of new studies modern and the postmodern. London: Routledge

Moscovici, S. (1988). Notes toward a description of social representations. European Journal of Social Psychology, (18):211-250.

Reid, A and Deaux, K. (1996). Relationship between social and personal identities: segregation or integration? Journal of Personality and Social Psychology. (71). 10841091.

Schiffrin, D. (1994). Approaches to discourse. Oxford: Blackwell

Stryker, S. (1987). Identity theory: developments and extensions. In Yardley, K. and Honess, T. (Eds.) Self and Identity: Psychosocial Perspectives. pp. 89-103. New York: Wiley.

Tajfel, H. (Ed.) 1982. Social identity and intergroup relations. Cambridge: Cambridge University Press

Tajfel, H., \& Turner, J. C. (1979). An integrative theory of inter-group conflict. In Austin, W. G. and Worchel, S. (Eds.) The social psychology of inter-group relations. pp. 33-47. Monterey: Brooks.

Vahid, H. and Esmae'Li, S. (2012). The power behind images: advertisement discourse in focus. International Journal of Linguistics. 4(4): 36-51

Wernick, A. (1991). Advertising, ideology and symbolic expression. London: Sage.

Williams, R. 1980. Problems in materialism and culture. London: NLB

Worchel, S. Iuzzini, J. Coutant, D. and Ivaldi, M. (2000). A multidimensional model of identity: Relating individual and group identities to intergroup behaviour. In Capozza, D. and Brown, R. (Eds.) Social identity processes: trends in theory and research. London: Sage Publications. 16-24

Young, L. and Harison, C. (2004). Systemic functional linguistics and critical discourse analysis: studies in social change. London: continuum. 